\title{
Granulocyte Macrophage Colony-stimulating Factor Contributes to Enhanced Monocyte Survival in Chronic Atopic Dermatitis
}

Donna L. Bratton, * Qutayba Hamid, ${ }^{5}$ Mark Boguniewicz, * Dennis E. Doherty, ${ }^{\ddagger 1}$ Jenai M. Kailey, * and Donald Y. M. Leung * Departments of $*$ Pediatrics, and ${ }^{\ddagger}$ Medicine, National Jewish Center for Immunology and Respiratory Medicine, Denver, Colorado 80206; ${ }^{\S}$ McGill University, Meakins-Christie Laboratories, Montreal, Quebec, PQ H2X 2P2, Canada; and "Service of Medicine, Denver Veteran's Administration Medical Center, Denver, Colorado 80220

\section{Abstract}

Evidence suggesting that prolonged effector cell survival may contribute to perpetuation of inflammation prompted us to ask whether monocyte macrophages, the predominate inflammatory cell in the lesion of chronic atopic dermatitis (AD), exhibit enhanced survival in AD. Cultures of peripheral blood monocytes from patients with chronic $A D$, psoriasis, and from normal (NL) donors were examined for morphologic features and DNA fragmentation characteristic of cells undergoing the process of apoptosis (programmed cell death). Cultures of AD monocytes exhibited a significantly lower incidence of apoptosis than did cultures of NL monocytes (45 vs $68 \%, P<0.01$ ), or psoriatic monocytes ( 45 vs $80 \%, P<0.01$ ). Furthermore, AD monocytes were unresponsive to both IL-1, an inhibitor of apoptosis, and IL-4, an enhancer of apoptosis, in comparison to cultured NL monocytes. Of note, GM-CSF in a concentration-dependent fashion, decreased the incidence of apoptosis in NL monocyte cultures and rendered them unresponsive to these cytokines. These findings suggested that GM-CSF may enhance monocyte survival in AD. In support of this hypothesis, AD monocyte cultures produced fivefold more GM-CSF than did cultures of NL monocytes or psoriatic monocytes ( $P$ $<0.05$ ). Additionally, there was a significantly greater number of GM-CSF mRNA expressing cells detected by in situ hybridization in biopsies of lesions of chronic $\mathrm{AD}$ than in acute AD or NL skin $(P<\mathbf{0 . 0 5})$. Finally, NL monocytes incubated with supernatants obtained from monocytes of AD patients exhibited significant inhibition of apoptosis, an effect that could be ablated by a neutralizing antibody to GM-CSF. Taken together, these data strongly suggest that increased production of GM-CSF by cells from patients with AD inhibits monocyte apoptosis and may contribute to the chronicity of this inflammatory disease. (J. Clin. Invest. 1995. 95:211-218.) Key words: apoptosis • GM-CSF • cytokine $\cdot$ monocyte $\cdot$ atopic dermatitis

Address correspondence to Donald Y. M. Leung, MD, Ph.D., Department of Pediatrics K926, National Jewish Center for Immunology and Respiratory Medicine, 1400 Jackson St., Denver, CO 80206. Phone: 303-398-1186; FAX: 303-398-1225.

Received for publication 7 March 1994 and in revised form 7 September 1994.

1. Abbreviations used in this paper: $\mathrm{AD}$, atopic dermatitis; $\mathrm{NL}$, normal; TTE, Tris-Triton EDTA.

The Journal of Clinical Investigation, Inc.

Volume 95, January 1995, 211-218

\section{Introduction}

Atopic dermatitis (AD) ${ }^{1}$ is a chronic inflammatory disease of the skin that frequently occurs in individuals with a personal or family history of atopy (1). Although AD is extremely common, affecting $10 \%$ of children and nearly $1 \%$ of the general population, the mechanism underlying this potentially debilitating chronic skin disease is poorly understood. On skin biopsy, the immunohistopathologic features depend on the stage of the lesion (2). Early lesions demonstrate marked intercellular edema (spongiosis) of the epidermis with dermal infiltrates of activated T lymphocytes that produce IL-4 and IL-5 (3-6). However, as lesions become more chronic, there is hyperplasia of the epidermis, with prominent hyperkeratosis and dermal fibrosis. Inflammatory infiltrates of the dermis in chronic lesions consist predominantly of monocyte macrophages (3).

Enhanced survival of inflammatory cells in inflamed tissues may be a factor in the establishment of chronic inflammation, and conversely, apoptosis or programmed cell death, of effector cells may contribute to the control or resolution of the inflammatory process $(7,8)$. The ability of phagocytes to engulf apoptotic cells so that intracellular contents are contained and not liberated to the extracellular milieu, allows the body to remove recruited effector cells in a noninflammatory manner (9). Recent data demonstrate that IL-4 enhances apoptosis of normal human monocytes following stimulation, and therefore may play an important role in control or resolution of inflammation (10).

Since chronic $\mathrm{AD}$ is associated with activation of circulating (11) and infiltrating monocytes (12), but also with increased production of IL-4 $(4,13)$ we hypothesized that monocytes from $\mathrm{AD}$ patients may have a paradoxical response to IL-4 with regard to survival. Indeed, in this study we found that cultures of peripheral blood monocytes from AD patients had a lower incidence of spontaneous apoptosis, and were unresponsive to IL-4-induced apoptosis after stimulation, in marked contrast to the responses of NL monocytes. Furthermore, the data demonstrate that the likely cause of this inhibition of apoptosis and nonresponsiveness to IL-4 is attributable to production of GMCSF by the circulating monocytes of AD patients. Finally, the demonstration of increased levels of GM-CSF mRNA in the inflammed tissues of $\mathrm{AD}$ suggests a role for this cytokine in contributing to the chronicity of this skin disease.

\section{Methods}

Reagents. The following cytokines were obtained: human rIL-4 from Dr. Paul Trotta (Schering Research Institute, Bloomfield, NJ); human rIL- $1 \alpha$, a kind gift from Hoffmann-La Roche, (Nutley, NJ), and IFN$\gamma$ from Genentech Inc. (South San Francisco, CA). Human rGM-CSF and monoclonal mouse antibody $\left(\mathrm{IgG}_{1}\right)$ to $\mathrm{rGM}-\mathrm{CSF}$ capable of total neutralization of $50 \mathrm{U}$ of GM-CSF bioactivity/ $\mu \mathrm{g}$ of antibody were purchased from Genzyme Corp. (Boston, MA). For quantification of 
GM-CSF from supernatants of cultured monocytes the Factor test human GM-CSF ELISA test kit (Genzyme Corp.) was used. Reagents employed were mouse monoclonal antibody to rGM-CSF as stationary antibody with rabbit anti-rGM-CSF antibody as a second antibody, and biotin-labeled goat anti-rabbit polyclonal antibody as the third antibody. DME and supplements were purchased from Whittaker M. A. Bioproducts, Inc. (Walkersville, MD). Agarose was obtained from Promega Corp. (Madison, WI); bromphenol blue from Bio Rad Laboratories (Richmond, CA); cDNA for GM-CSF from Glaxo Biogen (Geneva, Switzerland); and enzymes for in situ hybridization studies were purchased from Sigma Chemical Co. (St. Louis, MO).

"LPS-free" HSA was obtained from Biocell Laboratories (Carson, CA). Because LPS can inhibit apoptosis and result in activation of cultured monocytes, every effort was made to minimize exposure to LPS during monocyte isolation and assay procedures. Plasticware and reagents were tested for the presence of LPS with the Limulus amebocyte lysate kit (Associates of Cape Cod, Woods Hole, MA) and in all cases were less than $0.1 \mathrm{ng} / \mathrm{ml}$ LPS, a level at which inhibition of monocyte apoptosis (14) or activation (15) is not readily demonstrated.

Monocytes. Whole blood was obtained in accordance with Institutional Review Board approval from 12 healthy adult donors with no personal or family history of atopic disease, and eight adult patients with chronic severe $\mathrm{AD}$ involving $20-70 \%$ of skin surface area, diagnosed by the criteria of Hanifin and Rajka (16). All AD patients had coexisting respiratory allergy, either mild allergic rhinitis or asthma, not requiring maintenance medications. None of the AD patients had previously been treated with systemic corticosteroids. Topical corticosteroids were withheld for the $24 \mathrm{~h}$ before venipuncture. Additionally, as a skin disease control, monocytes were obtained from four adult donors with psoriasis vulgaris involving $30-60 \%$ of body surface area. Peripheral blood mononuclear leukocytes were obtained by discontinuous plasma-Percoll density gradient separation. Monocytes ( $>98 \%$ viable, $>85 \%$ yield) were further isolated by counterflow centrifugation-cell elutriation as has been previously published (15). Purity of the preparation of monocytes was $91.5 \pm 1.7$ (SD) \% as assessed by nonspecific esterase staining and was unchanged at time of harvesting cells from culture. Contaminating cells consisted of granulocytes $(0-7 \%)$ and lymphocytes $(0-6 \%)$ without differences between preparations obtained from AD and NL donors. Due to the limited and variable numbers of monocytes obtained from each donor, not all studies could be performed on cells obtained at a given time. For this reason, some donors were used on more than one occasion for different experiments. However, for any given experiment, a total of 3-10 donors were used with each donor studied only once.

Culture and co-culture conditions. Following the method of Mangan et al. (10), monocytes $\left(2 \times 10^{6} / 0.2 \mathrm{ml}\right)$ were suspended in DME containing $25 \mathrm{mM}$ glucose, $92 \mathrm{mM}$ gentamicin, $20 \mathrm{mM}$ L-glutamine, and $25 \mathrm{mM}$ Hepes buffer, $\mathrm{pH} 7.3$, in sterile $12 \times 75 \mathrm{~mm}$ polypropylene tubes. Cultures were incubated in high humidity at $37^{\circ} \mathrm{C}$ in $7.5 \% \mathrm{CO}_{2}$. Cytokines were diluted in media and added in the specified concentrations. For experiments employing GM-CSF, addition of $0.1 \%$ HSA to medium was necessary. In these experiments, appropriate controls with and without cytokines, were also incubated in the presence of $0.1 \%$ HSA which did not alter monocyte apoptosis in agreement with the findings of Mangan et al. (14). For co-culture experiments, fresh NL monocytes $\left(10 \times 10^{6}\right)$ were cultured in conditioned media with $0.1 \%$ HSA $(200 \mu \mathrm{l})$ harvested from AD monocytes $\left(10 \times 10^{6}\right)$ after $4 \mathrm{~h}$ incubation. When neutralizing antibody to GM-CSF was added to cocultures, it was added simultaneously with conditioned media at a concentration of $40 \mu \mathrm{g} / \mathrm{ml}$.

Morphological appearance of apoptosis. Two methods were used: (a) flow cytometry and $(b)$ light microscopy. For determination of apoptotic cells by flow cytometry, the method of Mangan and Wahl (17) with modifications described below was used. Samples $\left(10^{6}\right.$ cells $)$ were removed from cultures and suspended in media. Cells $(20,000$ events) were simultaneously analyzed on a 751 flow cytofluorograph (Coulter Electronics, Hialeah, FL) for forward scatter (a measure of cell size) and side scatter (a measure of granularity). Plots allowed separation of two cell populations, one smaller and less granular (apop- totic) and one larger and more granular (nonapoptotic). For determination of percentage of cells having undergone apoptosis by light microscopy, monocytes $\left(10^{5}\right)$ were harvested, cytospins prepared and stained with leukostat stain kit (Fisher Scientific Co., Pittsburgh, PA). Using the $\times 40$ objective, monocytes were scored as apoptotic or nonapoptotic in a blinded fashion by a single investigator (J. M. Kailey). 300 cells were counted from random fields for each specimen and the percent showing the morphological phenotype indicative of apoptosis expressed as a percentage of the total.

DNA fragmentation. The quantity of low molecular weight DNA as percentage of total DNA was determined by diphenylamine reaction as by the method of Burton (18). Monocytes $\left(3 \times 10^{6}\right)$ were lysed in Tris-Triton EDTA (TTE) and centrifuged at $13,000 \mathrm{~g}$ for $10 \mathrm{~min}$ at $4^{\circ} \mathrm{C}$. Pellets were resuspended in TCA $(5 \%)$ and heated at $90^{\circ} \mathrm{C}$ for 10 min. Samples were treated with diphenylamine $(15 \mathrm{mg} / \mathrm{ml})$, incubated at $22^{\circ} \mathrm{C}$ for $24 \mathrm{~h}$, and read at $570 \mathrm{~nm}$. DNA fragments from $10 \times 10^{6}$ monocytes were further characterized by electrophoresis in $2 \%$ agarose at $120 \mathrm{~V}$ for $6.5 \mathrm{~h}$ as by the method of Sambrook et al. (19). DNA markers Lambda HindIII and PhiX-174 HaelII (Promega Corp.) were used to assess the nucleosomal cleavage of DNA into characteristic 200 base pair multiple fragments.

Skin biopsies. A total of 19, 2-mm punch biopsy specimens were obtained from five adult patients with chronic lesions of $\mathrm{AD}$ (lichenified plaques of $>2$ wk duration); five adult patients with acute lesions of AD (erythematous papules, with or without evidence of transudate/ exudate, of $<3 \mathrm{~d}$ duration); five adult NL donors who had neither personal, nor family history of atopic disease; and four adult patients with chronic psoriasis. None of the subjects had other skin conditions and none had previously received oral steroids. Topical steroids were withheld for at least $2 \mathrm{wk}$ before biopsies were performed. Informed consent was obtained before all procedures and subjects were protected in accordance with IRB approval. Skin biopsies were fixed immediately in freshly prepared $4 \%$ paraformaldehyde for $2 \mathrm{~h}$, then washed twice ( $1 \mathrm{~h}$ each) with $15 \%$ sucrose in $0.1 \mathrm{M}$ phosphate-buffered saline, $\mathrm{pH}$ 7.4. Tissues were blocked with Tissue-Tek omithine carbamyl/transferase compound (Miles Inc., Elkhart, IN) and kept at $-80^{\circ} \mathrm{C}$ until used.

In situ hybridization for GM-CSF mRNA. In situ hybridization was performed as previously described (20-23). In brief, riboprobes, both antisense and sense were prepared from cDNA for GM-CSF. cDNA was inserted into the pGEM-1 vector and linearized with appropriate enzymes before transcription. Transcription was performed in the presence of $\left[{ }^{32} \mathrm{P}\right]$ UTP and T7 or SP6 RNA polymerases. Cryostat sections of biopsied tissue were permeabilized with Triton X-100 and proteinase $\mathrm{K}(1 \mu \mathrm{g} / \mathrm{ml})$ in $0.1 \mathrm{M}$ Tris containing $50 \mathrm{mM}$ EDTA for $15 \mathrm{~min}$ at $37^{\circ} \mathrm{C}$. To prevent nonspecific binding, the preparations were incubated with $10 \mathrm{mM}$ iodoacetamide for $30 \mathrm{~min}$ at $37^{\circ} \mathrm{C}$ and then in $0.5 \%$ acetic anhydride and $0.1 \mathrm{M}$ triethanolamine for $10 \mathrm{~min}$ at $37^{\circ} \mathrm{C}$. Prehybridization was carried out with $50 \%$ formamide and $2 \times$ SSC for 15 min at $40^{\circ} \mathrm{C}$. For hybridization, antisense or sense probes $\left(10^{6} \mathrm{cpm} /\right.$ section $)$ diluted in the hybridization buffer were used. Dithiothreitol ( $100 \mathrm{mM})$ was included in the hybridization mixture to ensure blocking of any further nonspecific binding of the probes. Posthybridization washing was performed in decreasing concentrations of SSC at $45^{\circ} \mathrm{C}$. Unhybridized single-strand RNAs were removed by RNase A $(20 \mu \mathrm{g} / \mathrm{ml})$. After dehydration, the sections were immersed in nitro/blue tetrazolium emulsion and exposed for $12 \mathrm{~d}$. The autoradiographs were developed in Kodak D-19, fixed, and counterstained with hematoxylin.

For negative controls, skin biopsies were hybridized as above using a GM-CSF sense probe. In addition, sections were treated with RNase A before the prehybridization step with the antisense probe. Specific hybridization was recognized as clear dense deposits of silver grains in the photographic emulsion overlaying the tissue sections. Cells were identified as dense, discrete, well circumscribed areas of silver grains. When hybridizing cells were in close proximity, their numbers were determined by visualizing the individual nuclei using dark field illumination. Positive cells were only observed with the antisense probe. Preparations treated with the sense probe or pretreated with RNase were negative with no specific signals.

Slides were encoded and positive cells counted blindly by one inves- 


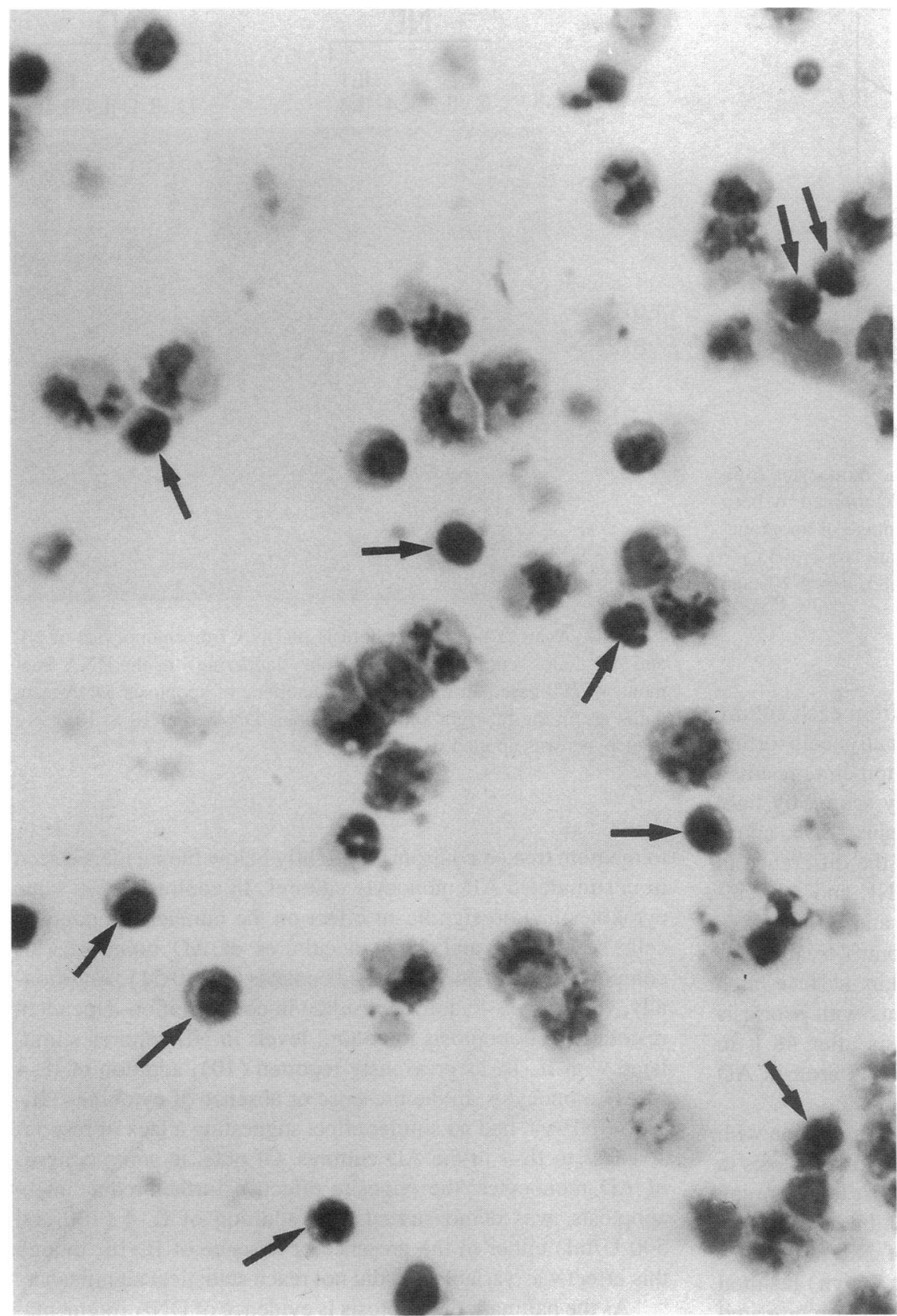

Figure 1. Photomicrograph of apoptotic (arrows) and nonapoptotic NL monocytes after $24 \mathrm{~h}$ of culture. Apoptotic monocytes having lost abundant cytoplasm are smaller than nonapoptotic monocytes and demonstrate nuclear condensation $(\times 100)$ tigator ( $Q$. Hamid) using an Olympus microscope at $\times 100$ with an eyepiece graticule. The results were expressed as the mean number of positive cells/field. The within observer coefficient of variation for repeated measures was $<5 \%$.

Statistics. Statistical analysis was carried out by a repeated measures analysis of variance model with cytokine treatment, subject group, and the interaction between cytokine treatments and subject groups used as the independent variables. Specific procedures are described in the figure legends for each data set. Comparisons of GM-CSF measured in supernatants from monocytes of NL, AD, and psoriasis patients were performed using a Kruskal-Wallis test, a nonparametric analogue of the one-way analysis of variance.

\section{Results}

Cultured monocytes from $A D$ patients demonstrate a lower incidence of apoptosis than monocytes from normal donors and fail to undergo apoptosis in response to $I L-4$. Monocytes of both
NL donors and $A D$ patients were placed in serum-free culture for up to $48 \mathrm{~h}$. Apoptotic monocytes from both NL and AD cultures were readily identified by light microscopy after $24 \mathrm{~h}$. However, there was significantly greater numbers of apoptotic monocytes in NL cultures than $\mathrm{AD}$ cultures $(31.8 \pm 6.1 \mathrm{com}-$ pared to $15.2 \pm 2.9 \%$, respectively, means \pm SD, $P<0.001$ by univariate ANOVA). Monocytes having undergone apoptosis were identified by their shrunken appearance with marked loss of cytoplasm and nuclear condensation (Fig. 1). All microscopic analyses were done by a blinded observer. Apoptotic monocytes were also quantified by flow cytometry using the method of Mangan et al. (10). Analysis of cultured monocytes by flow cytometry at $48 \mathrm{~h}$ demonstrated that the two populations, apoptotic and nonapoptotic, could be readily distinguished from each other by the smaller size and diminished granularity of the apoptotic monocytes. Furthermore, comparison of the two methods, light microscopy and flow cytometry, for quanti- 


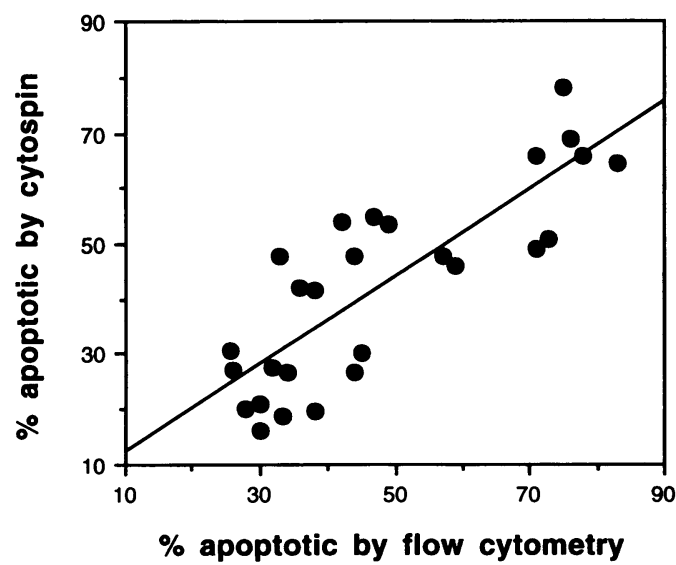

Figure 2. The number of apoptotic and nonapoptotic monocytes from $\mathrm{NL}$ and AD cultures incubated for 16-48 $\mathrm{h}$ were determined by both light microscopy and flow cytometry and the percentage of apoptotic cells plotted for each method. Overall line of the data is $y=6.35$ $+0.75 x$ with a Pearson correlation coefficient of 0.83. $n=4 \mathrm{NL}$ and $\mathrm{AD}$ donors each.

fying the percentage of apoptotic monocytes from each culture resulted in good correlation (Fig. 2). Additionally, cell sorting of the two populations identified by flow cytometry, resulted. in isolated populations that were subsequently scored by light microscopy as $97.8 \pm 3.3$ and $91.0 \pm 3.5 \%$ (means \pm SD), apoptotic and nonapoptotic, respectively. At $48 \mathrm{~h}$, the difference in percentage of apoptotic monocytes between NL and AD cultures was again significant at $68.1 \pm 7.7$ and $44.9 \pm 7.7 \%$ ( mean \pm SD; $P<0.01$ ), respectively (Fig. 3, control treatment). Additionally, in spite of having similar skin surface area involvement, monocytes obtained from patients with psoriasis exhibited an incidence of $80.0 \pm 3.35$ apoptosis after $48 \mathrm{~h}$ in culture, significantly higher $(P<0.01)$ than that seen in $\mathrm{AD}$ cultures, and not dissimilar from NL donors.

As previous studies have demonstrated that stimulation with IL-1 and several other stimuli inhibits the process of apoptosis in normal monocytes $(10,14,17)$, it was of interest to determine whether cytokine stimulation would further inhibit apoptosis in monocytes from AD patients. Stimulation of NL monocytes with either IL-1 $\alpha$ (Fig. 3) or IFN- $\gamma$ (data not shown) resulted in a significant decrease in apoptosis $(P=0.005$, as compared

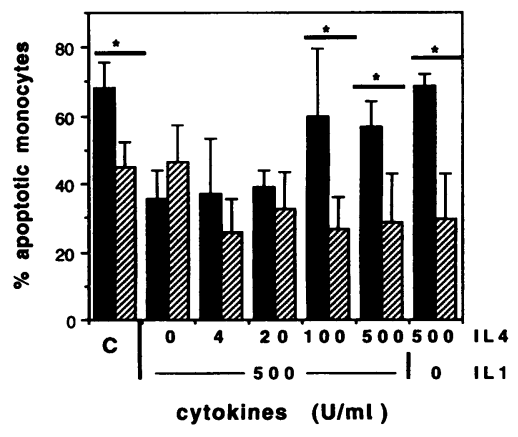

Figure 3. Apoptosis of $\mathrm{NL}(\boldsymbol{\square})$ and $\mathrm{AD}(\boldsymbol{\square})$ monocytes with and without various combinations of IL-1 and IL-4 $(\mathrm{U} / \mathrm{ml})$. Means $\pm \mathrm{SD}$ shown. *Notes significant difference between indicated pairs $(P$ $<0.01$ by repeated measures ANOVA). Within group comparisons showed that NL mono-

cytes treated with IL-1 alone, or IL-1 with either 4 or $20 \mathrm{U} / \mathrm{ml} \mathrm{IL-4}$ differed significantly from medium-treated $(C) \mathrm{NL}$ monocytes $(P$ $<0.005$ by Dunnett's multiple comparisons procedure). For AD monocytes there were no significant differences between treatments $(P$ $=0.54) . n=5 \mathrm{NL}$ and $\mathrm{AD}$ donors each.

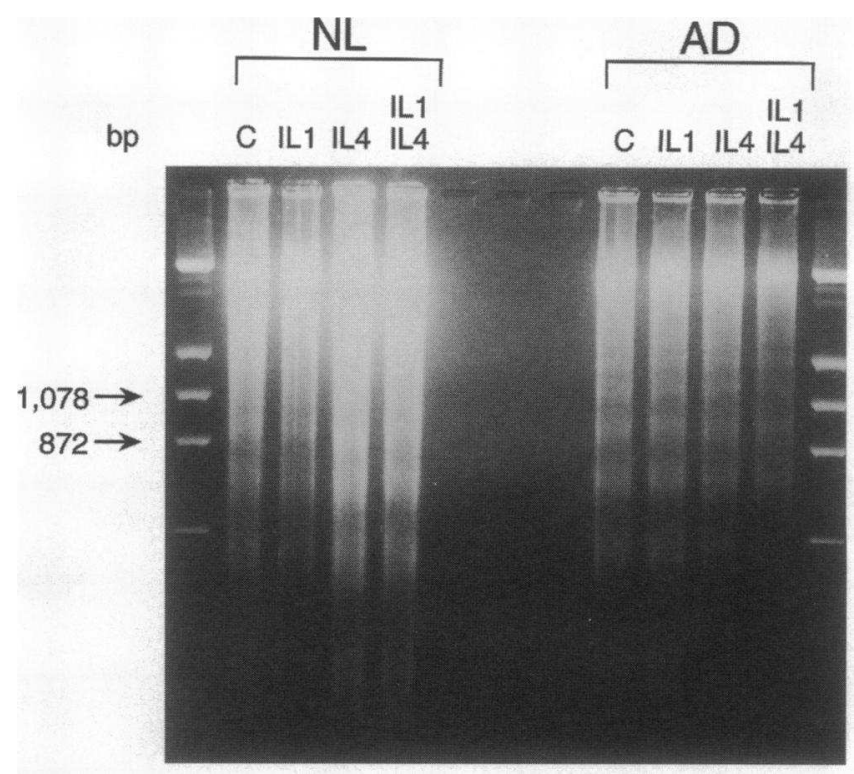

Figure 4. Agarose gel electrophoresis of DNA from monocytes of NL and AD donors cultured for $48 \mathrm{~h}$. Note "laddering" of the DNA fragments of 200 base pair multiples characteristic of apoptosis. DNA standards are in the far right and far left lanes. DNA from $10 \times 10^{6}$ monocytes was applied to each lane.

to medium treated controls) to slightly below the incidence seen in unstimulated $\mathrm{AD}$ monocyte cultures. In contrast, these same cytokines had no significant effect on the number of apoptotic cells seen at 24 and $48 \mathrm{~h}$ in cultures of $\mathrm{AD}$ monocytes as compared to the medium-treated controls $(P=0.54)$. Additionally, whereas IL-4 addition resulted in concentration-dependent restoration of apoptosis to control levels in NL cultures stimulated with IL-1 $\alpha$ as previously reported (10), addition of IL-4 to $\mathrm{AD}$ monocytes, in the presence or absence of cytokines (IL$1 \alpha$ or INF- $\gamma$ ), had no similar effect suggesting a lack of responsiveness to IL-4 in the AD cultures. Of note, in some cultures of $\mathrm{AD}$ monocytes, the opposite effect, a further reduction in apoptosis, was demonstrated with addition of IL-4 (100 and $500 \mathrm{U} / \mathrm{ml}$ ) either in the presence or absence of IL- $1 \alpha$, though this effect was variable and did not reach statistical significance.

As the hallmark of apoptosis is evidence of DNA fragmentation into characteristic 200 base pair ladders, additional evidence of DNA fragmentation was correlated with the morphological features of apoptosis. Quantification of low molecular weight DNA by the diphenylamine reaction was performed at various times for both NL and AD cultures incubated in the presence and absence of cytokines. In this regard, a significant correlation was found between the quantity of low molecular DNA and the number of apoptotic monocytes from each culture (data fit to the overall line of $y=17.09+0.65 x$, with slope significant at $P<0.01$ by mixed effects ANOVA model). Furthermore, and though not quantitative, gel electrophoresis of DNA from both AD and NL monocyte cultures did demonstrate the presence of DNA cleavage into fragments of 200 base pair multiples (Fig. 4).

Evidence that inhibition of monocyte apoptosis is due to endogenous GM-CSF production by monocytes in patients with $A D$. The paradoxical finding of the lack of responsiveness by $\mathrm{AD}$ monocytes to IL-4, a cytokine present in the milieu of $\mathrm{AD}$ $(4,5,13)$, prompted us to ask what other cytokine(s) might 

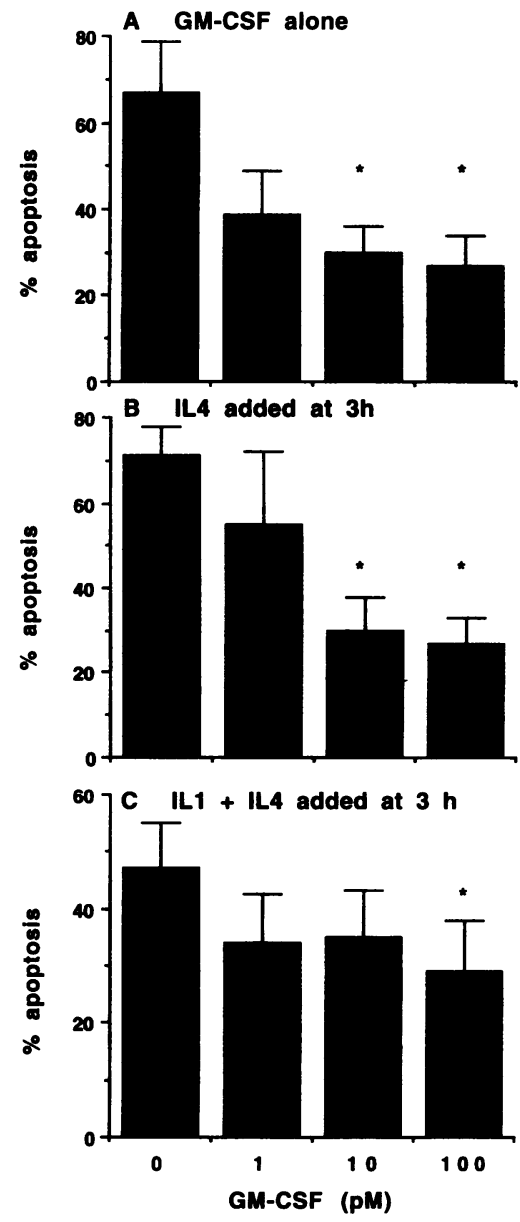

Figure 5. GM-CSF inhibition of apoptosis of $\mathrm{NL}$ monocytes. GM-CSF alone added to fresh monocytes resulted in concentration-dependent inhibition of apoptosis at $48 \mathrm{~h}(A)$. Neither IL-4 $(100 \mathrm{U} / \mathrm{ml})$ $(B)$, nor IL-1 (500 U/ $\mathrm{ml})$ with IL-4 ( $100 \mathrm{U} /$ $\mathrm{ml})(C)$ added at $3 \mathrm{~h}$ into the incubation in the presence of GM-CSF restored baseline apoptosis. The percentage of cells undergoing apoptosis was determined by the cytospin method. Means $\pm S D$ are shown. For each data set, * notes significant differences $P<0.01$ from control incubation in the absence of GM-CSF as determined by a univariate repeated measures ANOVA and the Tukey's multiple comparisons procedure. $n=3-5$ donors.

be identified that could alter IL-4 responsiveness. Earlier studies demonstrating that activated monocytes can produce GM-CSF (24), and that $\mathrm{AD}$ monocytes in the blood and infiltrating skin lesions express CD23, a surface molecule inducable by GMCSF $(25,26)$, prompted us to ask whether GM-CSF might play such a role. Initially, NL monocytes were tested in the presence of GM-CSF to see if the growth factor would alter cytokine responses to resemble those of $\mathrm{AD}$ monocytes. As shown in Fig. $5 \mathrm{~A}$, a significant dose-dependent reduction in apoptosis at $48 \mathrm{~h}$ was seen in NL monocyte cultures treated with GM-CSF. Of note, however, treatment of NL monocytes with GM-CSF followed by either IL-4, or IL1 $\alpha$ with IL-4 (Fig. $5 B$ and $C$ ), did not restore the high incidence of apoptosis seen in the absence of GM-CSF. This pattern of unresponsiveness by NL monocytes to IL-4 or the combination of IL-1 with IL-4 in the presence of GM-CSF, was very similar to that seen in IL-1 and IL-4treated AD monocytes (compare with Fig. 3).

As a proof of concept, cultures of $\mathrm{AD}$ monocytes were therefore assessed for evidence of endogenous production of GM-CSF. GM-CSF was detected in four out of four supernatants of cultured AD monocytes and appeared to peak at $4 \mathrm{~h}$ of culture at a level of $228 \pm 150$ (mean $\pm S D$ ) $\mathrm{pg} / 10^{7}$ monocytes. By comparison, GM-CSF measured in 12 NL culture supernatants was not detectable in six, and found to be $44 \pm 58$ (mean $\pm \mathrm{SD}$ ) $\mathrm{pg} / 10^{7}$ monocytes in the remaining six cultures $(P<0.05)$. Additionally, no GM-CSF was detected in the supernatant from monocytes from the four patients with psoriasis. Importantly, skin biopsies of acute and chronic $\mathrm{AD}$, as well as psoriatic lesions and normal skin from NL controls, were

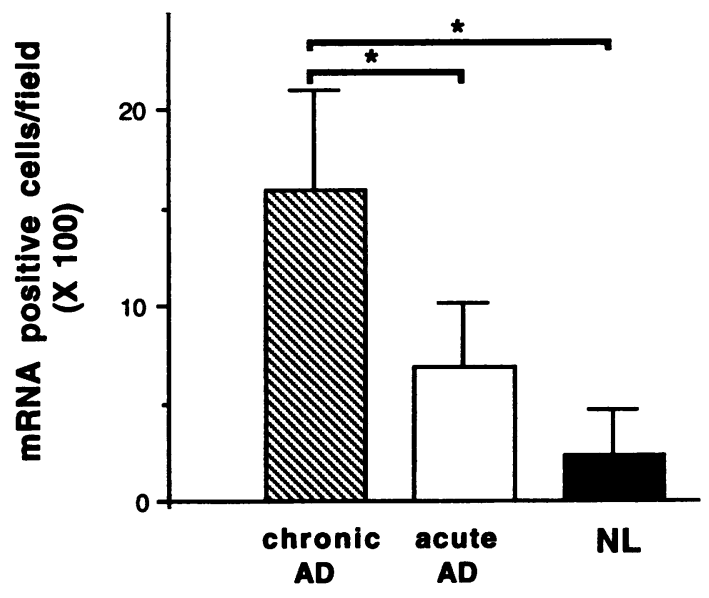

Figure 6. GM-CSF mRNA positive cells/field $(\times 100)$ detected by in situ hybridization in biopsied lesions of chronic $A D$ vs acute $A D$ vs skin of NL donors. Mean \pm SD shown. $n=5$ each group. ${ }^{*}$ No. of cells expressing GM-CSF mRNA in chronic AD was significantly different $(P<0.05$, by univariate ANOVA and multiple comparisons procedure $)$ than either acute AD or NL skin, which did not differ from each other.

examined by in situ hybridization for GM-CSF mRNA. As shown, a significantly greater number of GM-CSF mRNA positive cells $(P<0.05)$ were identified in lesions of chronic $\mathrm{AD}$ than in lesions of acute $\mathrm{AD}$ or control skin biopsies from NL donors (Fig. 6). The GM-CSF mRNA positive cells in chronic $\mathrm{AD}$ were distributed mainly in the dermis where monocyte macrophages predominate in chronic $\mathrm{AD}$ skin lesions (3) (Fig. 7). However, the absolute identity of the cells positive for GMCSF mRNA was not determined in these studies and may include $\mathrm{T}$ cells, mast cells, and keratinocytes in addition to the monocyte macrophage. Of note, GM-CSF mRNA positive cells were also present in lesions of chronic psoriasis with similar frequency as compared to that of chronic $\mathrm{AD}(12.5 \pm 3.1 \mathrm{com}-$ pared to $16.0 \pm 5.0 \mathrm{GM}-\mathrm{CSF}$ mRNA positive cells/high power field, means $\pm \mathrm{SD}$, respectively), demonstrating that GM-CSF produced in tissue is likely to play a role in a variety of chronic skin diseases (see Discussion).

Finally, as a test of whether supernatants from cultured AD monocytes could inhibit NL monocyte apoptosis, conditioned media were harvested from 4-h cultures of $\mathrm{AD}$ monocytes and used to treat fresh NL monocytes. Indeed, at $48 \mathrm{~h}$, a significant decrease in apoptosis was demonstrated in NL monocytes cultured with AD supernatant as compared to NL supernatant (Fig. 8). Importantly, the incidence of apoptosis was restored to that seen in control cultures when cultures were treated with $A D$ supernatant and a neutralizing antibody to GM-CSF. Taken together, these data support the hypothesis that $\mathrm{AD}$ monocytes both produce, and are stimulated by GM-CSF, and that such stimulation results in dysregulation of both baseline apoptosis, and cytokine (IL-4) induction of apoptosis.

\section{Discussion}

Despite the common occurrence of $\mathrm{AD}$ in the general population, the events that lead to perpetuation of skin inflammation in this disease are poorly understood. An understanding of this process may provide important new directions for its treatment. Early inflammatory events likely lead to the generation of proinflammatory cytokines and mediators, the upregulation of adhe- 

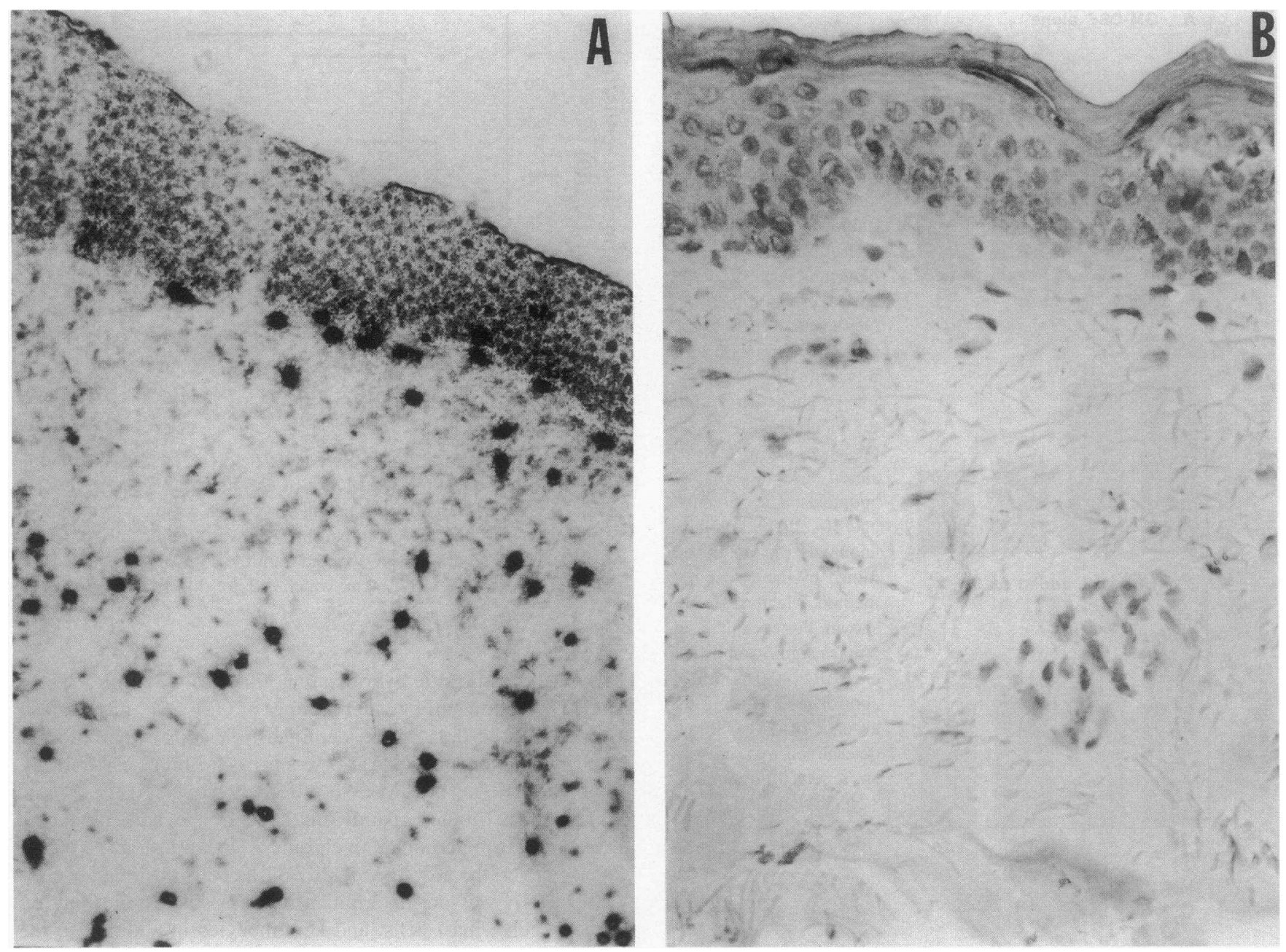

Figure 7. Photomicrograph of skin biopsies of a chronic AD lesion $(A)$ and normal skin $(B)$ demonstrating increased staining for GM-CSF mRNA within cells predominately located in the dermis of AD skin $(\times 200)$.

sion molecules on endothelium and recruitment of new inflammatory cells. Activated (HLA-DR and IL-2R bearing) Th2 type T cells likely produce IL-4 and IL-5 (4-6) while activated resident mast cells or keratinocytes produce IL-1 and TNF$\alpha$, resulting in the upregulation of E-selectin and intracellular adhesion molecule on endothelium $(27,28)$. This results in the subsequent recruitment of inflammatory effector cells such as monocytes, and eosinophils (1). Emerging evidence shows that signals in the form of growth factors, cytokines, and the extra-

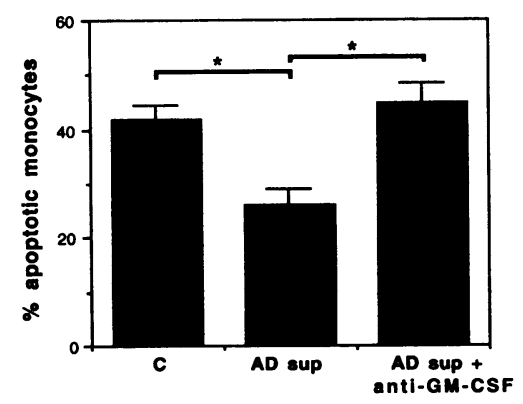

Figure 8. Conditioned media ( sup) from cultures of $\mathrm{AD}$ monocytes significantly inhibits apoptosis of NL monocytes. Addition of antiGM-CSF ( $40 \mu \mathrm{g} / \mathrm{ml})$ abolishes the inhibitory effect of the AD sup. $* P<0.01$, as determined by a univariate repeated measures

ANOVA with a Tukey's multiple comparisons procedure. Means \pm SD shown. $n=3 \mathrm{NL}$ and $3 \mathrm{AD}$ donors. cellular matrix markedly enhance both the inflammatory potential and longevity of these recruited effector cells $(10,14,17$, 29,30 ). Though the monocyte macrophage is obviously only one inflammatory cell in the complex inflammatory process described above, the predominance of these cells in the established lesions of chronic $\mathrm{AD}$, and the known proinflammatory activities of these cells suggest they may have an important role in the perpetuation of inflammation in $\mathrm{AD}$ (3). Furthermore, the finding of enhanced monocyte longevity presented here may also be applicable to other diseases such as idiopathic pulmonary fibrosis and asthma where monocyte macrophage infiltrates are prominent.

The hypothesis that dysregulation of monocyte apoptosis and hence enhanced survival of monocytes occurs in chronic $\mathrm{AD}$, is supported by the data presented in this paper. Specifically, our data demonstrate that cultures of peripheral blood monocytes of $\mathrm{AD}$ patients exhibit decreased numbers of cells undergoing apoptosis when compared to cultures of normal monocytes (Fig. 3) and monocytes obtained from patients with psoriasis. Furthermore, the inhibition of apoptosis in NL monocytes, both baseline and cytokine (IL-4)-induced, following treatment with either GM-CSF (Fig. 5) or conditioned media from $\mathrm{AD}$ monocytes (Fig. 7), suggested that the difference in GM-CSF production between NL and AD monocytes is the 
basis for these phenomena. Heightened secretion of GM-CSF from circulating $\mathrm{AD}$ monocytes in comparison to that of NLs and psoriasis patients, and the finding of increased levels of GM-CSF mRNA expression by in situ hybridization in the inflammatory cell infiltrate of chronic $\mathrm{AD}$, as compared to the acute $\mathrm{AD}$ skin lesion (Fig. 6), was demonstrated. These data support the hypothesis that monocytes in $\mathrm{AD}$ are uniquely stimulated by GM-CSF in the blood, by either an autocrine or intracrine mechanism, and also stimulated by GM-CSF in the tissues of $\mathrm{AD}$. Thus, this cytokine may be important in development of long-standing $\mathrm{AD}$ inflammation. Additionally, the finding of increased GM-CSF mRNA in psoriasis suggests the likelihood that GM-CSF inhibits apoptosis of the monocyte macrophage and other granulocytes in the local milieu, and thereby can perpetuate chronic inflammation in other skin conditions not restricted to $\mathrm{AD}$.

The findings by Mangan et al. (10) and the data here, demonstrating that IL-4 enhances apoptosis of NL monocytes following stimulation with $\mathrm{IL}-1$, suggest that this response to $\mathrm{IL}$ 4 may contribute to resolution of inflammation. Though it is known that IL-4 stimulation can result in decoy expression of the IL-1 receptor type II, and thereby mitigate the effects of $\mathrm{IL}$ 1 (31), it should be noted that IL-4 also promotes apoptosis in monocytes stimulated with LPS and TNF- $\alpha$ (14). Thus IL-4 may promote monocyte apoptosis as an anti-inflammatory effect in certain clinical settings. That IL-4 is present and likely to play a role in $\mathrm{AD}$ is suggested by the demonstration of both enhanced secretion of IL- 4 by Th2 type T cells and increased IL-4 receptor density on these cells obtained from $A D$ patients (4). Furthermore, the presence of elevated IgE production from B cells which can be blocked by anti-IL-4, and the presence of CD23 on monocytes and other cells are likely consequences of in vivo $\mathrm{IL}-4$ production in $\mathrm{AD}(32-34)$.

The finding that monocytes from AD patients do not undergo apoptosis to IL-4 after stimulation was a novel and surprising finding in this study and suggests that this anti-inflammatory effect of IL-4 is not manifest in $A D$, despite the fact that other pro-inflammatory activities of IL-4 predominate. The demonstration that GM-CSF treatment of NL monocytes results in abrogation of IL-4-induced monocyte apoptosis, taken together with the evidence for the presence of GM-CSF in AD may suggest one mechanism for perpetuation of the skin inflammation in $\mathrm{AD}$. The complete restoration of apoptosis in NL monocytes co-cultured with AD-conditioned media after the addition of neutralizing antibody to GM-CSF is strong evidence that GM-CSF alone, and not another cytokine, is responsible for the demonstrated monocyte longevity.

The altered cytokine responses and GM-CSF production by circulating $\mathrm{AD}$ monocytes presented here are consistent with previous studies demonstrating activation of circulating monocytes in AD. Previous data demonstrating that circulating monocytes are primed for superoxide production (11), may also be a consequence of generation of GM-CSF (35). GM-CSF has also been reported to induce CD23 expression on peripheral blood monocytes (26). The increased production of GM-CSF in $\mathrm{AD}$ may also contribute to the increased eosinophilia and deposition of eosinophil granule proteins in this disease (3638). At present, the mechanism for increased GM-CSF production by monocyte macrophages is not well understood. One likely possibility, however, may relate to increased allergen and/or staphylococcal toxin exposure as both stimuli can act as macrophage activators and are known triggers for $\mathrm{AD}$ (12).

In conclusion, this study demonstrates that enhanced sur- vival of monocytes may contribute to the predominance of monocyte macrophage infiltration of chronic AD. The generation of GM-CSF with its pleuripotential inflammatory roles for both priming cellular responses and in enhancing survival of cells in the granulocyte and monocyte lineages likely augments and perpetuates inflammation due to monocytes, mast cells, eosinophils, and basophils $(36,38-40)$. Furthermore, dysregulation of monocyte apoptosis may contribute to perpetuation of inflammatory cell infiltration, prevent antiinflammatory events that might result in resolution of inflammation, and ultimately lead to chronic allergic disease.

\section{Acknowledgments}

The authors would like to thank Dannette Martin for assistance in the collection of patient blood samples and skin biopsies, Georgia Wheeler for secretarial assistance, and Dr. Lynn Ackerson for her assistance with statistical analysis. This work was supported in part by National Institutes of Health grants GM-48211-01, AR-41256, HL-36577, HL-27353, RR-00051, and HL-37260.

\section{References}

1. Leung, D. Y. M. 1992. Immunopathology of atopic dermatitis. Springer Semin. Immunopathol. 12:427-440.

2. Mihm, M. C., N. A. Soter, H. F. Dvorak, and K. F. Austen. 1976. The structure of normal skin and the morphology of atopic eczema. J. Invest. Dermatol. 67:305-312.

3. Leung, D. Y. M., A. K. Bhan, E. E. Schneeberger, and R. S. Geha. 1983 Characterization of the mononuclear cell infiltrate in atopic dermatitis using monoclonal antibodies. J. Allergy Clin. Immunol. 71:47-56.

4. Renz, H., K. Jujo, K. L. Bradley, J. Domenico, E. W. Gelfand, and D. Y. M. Leung. 1992. Enhanced IL-4 production and IL-4 receptor expression in atopic dermatitis and their modulation by interferon-gamma. J. Invest. Dermatol. 99:403-408.

5. Sager, N., A. Feldmann, G. Schilling, P. Kreitsch, and C. Neumann. 1992. House dust mite-specific $T$ cells in the skin of subjects with atopic dermatitis frequency and lymphokine profile in the allergen patch test. J. Allergy Clin. Immunol. 89:801-810.

6. van Reijsen, F. C., C. A. F. M. Bruijnzeel-Koomen, F. S. Kalthoff, E Maggi, S. Romagnani, J. K. T. Westland, and G. C. Mudde. 1992. Skin-derived aeroallergen-specific $\mathrm{T}$-cell clones of $\mathrm{Th} 2$ phenotype in patients with atopic dermatitis. J. Allergy Clin. Immunol. 90:184-192.

7. Cohen, J. J., R. C. Duke, V. A. Fadok, and K. S. Sellins. 1992. Apoptosis and programmed cell death in immunity. Annu. Rev. Immunol. 10:267-293.

8. Haslett, C. 1992. Resolution of acute inflammation and the role of apoptosis in the tissue fate of granulocytes [editorial]. Clin. Sci. (Lond.). 83:639-648.

9. Savill, J., V. Fadok, P. Henson, and C. Haslett. 1993. Phagocyte recognition of cells undergoing apoptosis. Immunol. Today. 14:131-136.

10. Mangan, D. F., B. Robertson, and S. M. Wahl. 1992. IL-4 enhances programmed cell death (apoptosis) in stimulated human monocytes. J. Immunol. 148:1812-1816.

11. Polla, B. S., R. A. Ezekowitz, and D. Y. M. Leung. 1992. Monocytes from patients with atopic dermatitis are primed for superoxide production. $J$. Allergy Clin. Immunol. 89:545-551.

12. Leung, D. Y. M., A. R. Rhodes, R. S. Geha, L. Schneider, and J. Ring. 1993. Atopic dermatitis. In Dermatology in General Medicine. T. B. Fitzpatrick, A. Z. Eisen, K. Wolff, I. M. Freeberg, and K. F. Austen, editors. 4th ed. McGrawHill Inc., New York. 1543-1564.

13. Jujo, K., H. Renz, J. Abe, E. W. Gelfand, and D. Y. M. Leung. 1992. Decreased interferon gamma and increased interleukin-4 production in atopic dermatitis promotes IgE synthesis. J. Allergy Clin. Immunol. 90:323-331.

14. Mangan, D. F., G. R. Welch, and S. M. Wahl. 1991. Lipopolysaccharide tumor necrosis factor- $\alpha$, and IL- $1 \beta$ prevent programmed cell death (apoptosis) in human peripheral blood monocytes. J. Immunol. 146:1541-1546.

15. Doherty, D. E., C. Haslett, M. G. Tonnesen, and P. M. Henson. 1987. Human monocyte adherence: a primary effect of chemotactic factors on the monocyte to stimulate adherence to human endothelium. J. Immunol. 138:1762-1771.

16. Hanifin, J. M., and G. Rajka. 1980. Diagnostic features of atopic dermatitis Acta Dermato-Venereol. 92(Suppl):44-47.

17. Mangan, D. F., and S. M. Wahl. 1991. Differential regulation of human monocyte programmed cell death (apoptosis) by chemotactic factors and proinflammatory cytokines. J. Immunol. 147:3408-3412.

18. Burton, K. 1956. A study of the conditions and mechanisms of diphenylamine reaction for the colorimetric estimation of DNA. Biochem. J. 62:315-323. 
19. Sambrook, J., E. F. Fritsch, and T. Maniatis. 1989. Molecular Cloning: A Laboratory Manual. 2nd ed. Cold Spring Harbor Laboratory, Cold Spring Harbor, NY. 589 pp.

20. Hamid, Q., J. Wharton, G. Terenghi, C. Hassal, J. Aimi, K. Taylor, H. Nakazato, J. Dixon, G. Burnstock, and J. M. Poak. 1987. Localization of natiuretic peptic mRNA and immunoreactivity in rat heart and human arterial appendage. Proc. Natl. Acad. Sci. USA. 84:6760-6764.

21. Hamid, Q., M. Azzawi, S. Ying, R. Moqbel, A. J. Wardlaw, C. J. Corrigan, B. Bradley, S. R. Durham, J. V. Collins, P. K. Jeffery, D. J. Quint, and A. B. Kay. 1991. Expression of mRNA for interleukin-5 in mucosal bronchial biopsies from asthma. J. Clin. Invest. 87:1541-1546.

22. Robinson, D. S., Q. Hamid, S. Ying, A. Tsicopoulos, J. Barkans, A. M. Bentley, C. Corrigan, S. R. Durham, and A. B. Kay. 1992. Predominant $\mathrm{T}_{\mathrm{H} 2}$-like bronchoalveolar T-lymphocyte population in atopic asthma. N. Engl. J. Med. 326:298-304.

23. Kay, A. B., S. Ying, V. Varney, M. Gaga, S. R. Durham, R. Moqbel, A. J. Wardlaw, and Q. Hamid. 1991. Messenger RNA expression of cytokine gene cluster, interleukin 3 (IL-3), IL-4, IL-5, and granulocyte/macrophage colonystimulating factor, in allergen-induced late-phase cutaneous reactions in atopic subjects. J. Exp. Med. 173:775-778.

24. Groopman, J. E., J.-M. Molina, and D. R. Scadden. 1989. Hematopoietic growth factors. Biology and clinical applications. N. Engl. J. Med. 321:14491459.

25. Leung, D. Y. M. E. E. Schneeberger, R. P. Siraganian, R. S. Geha, and A. K. Bhan. 1987. The presence of IgE on monocytes/macrophages infiltrating into the skin lesion of atopic dermatitis. Clin. Immunol. Immunopathol. 42:328337.

26. Williams, J., S. Johnson, J. J. Mascali, H. Smith, L. J. Rosenwasser, and L. Borish. 1992. Regulation of low affinity IgE receptor (CD23) expression on mononuclear phagocytes in normal and asthmatic subjects. J. Immunol. 149:2823-2829.

27. Leung, D. Y. M., J. S. Pober, and R. S. Cotran. 1991. Expression of endothelial-leukocyte adhesion molecule- 1 in elicited late phase allergic reactions. J. Clin. Invest. 87:1805-1809.

28. Kyan-Aung, U., D. O. Haskard, R. N. Poston, M. H. Thornhill, and T. H. Lee. 1991. Endothelial leukocyte adhesion molecule-1 and intercellular adhesion molecule-1 mediate the adhesion of eosinophils to endothelial cells in vitro and are expressed by endothelium in allergic cutaneous inflammation in vivo. $J$. Immunol. 146:521-528.

29. Colotta, F., F. Re, N. Polentarutti, S. Sozzani, and A. Mantovani. 1992. Modulation of granulocyte survival and programmed cell death by cytokines and bacterial products. Blood. 80:2012-2020.

30. Anwar, A. R. F., R. Moqbel, G. M. Walsh, A. B. Kay, and A. J. Wardlaw. 1993. Adhesion to fibronectin prolongs eosinophil survival. J. Exp. Med. 177:839-843.
31. Colotta, F., F. Re, M. Muzio, R. Bertini, N. Polentarutti, M. Sironi, J. G. Giri, S. K. Dower, J. E. Sims, and A. Mantovani. 1993. Interleukin-1 type II receptor: a decoy target for IL-1 that is regulated by IL-4. Science (Wash. DC). 261:472-475.

32. Vercelli, D., H. H. Jabara, B.-W. Lee, N. Woodland, R. S. Geha, and D. Y. M. Leung. 1988. Human recombinant interleukin 4 induces Fc $\epsilon$ R2/CD23 on normal human monocytes. J. Exp. Med. 167:1406-1416.

33. Rousset, F., J. Robert, M. Andary, J.-P. Bonnin, G. Souillet, I. Chrétien, F. Briére, J. Péne, and J. E. de Vries. 1991. Shifts in interleukin-4 and interferon$\gamma$ production by $\mathrm{T}$ cells of patients with elevated serum IgE levels and the modulatory effects of these lymphokines on spontaneous IgE synthesis. J. Allergy Clin. Immunol. 87:58-69.

34. Vollenweider, S. J.-H. Saurat, M. Rocken, and C. Hauser. 1991. Evidence suggesting involvement of interleukin-4 (IL-4) production in spontaneous in vitro IgE synthesis in patients with atopic dermatitis. J. Allergy Clin. Immunol. 87:1088-1095.

35. Roux-Lombard, P., A. Cruchaud, and J. M. Dayer. 1986. Effect of interferon gamma and 1,25-dihydroxyvitamin $D_{3}$ on superoxide anion, prostaglandin $\mathrm{E}_{2}$, and mononuclear cell factor production by U937 cells. Cell. Immunol. 97:286296.

36. Burke, L. A., M. P. Hallsworth, T. M. Litchfield, R. Davidson, and T. H. Lee. 1991. Identification of the major activity derived from cultured human peripheral blood mononuclear cells, which enhances eosinophil viability, as granulocyte macrophage colony-stimulating factor (GM-CSF). J. Allergy Clin. Immunol. 88:226-235

37. Leiferman, K. M., S. J. Ackerman, H. A. Sampson, H. S. Haugen, P. Y. Venecie, and G. J. Gleich. 1985. Dermal deposition of eosinophil granule major basic protein in atopic dermatitis: Comparison with onchocerciasis. $N$. Engl. J. Med. 313:282-285.

38. Lopez, A. F., D. J. Williamson, J. R. Gamble, C. G. Begley, J. M. Harlan, S. J. Klebanoff, A. Waltersdorph, G. Wong, S. C. Clark, and M. A. Valdas. 1986 Recombinant human granulocyte-macrophage colony-stimulating factor stimulates in vitro mature human neutrophil and eosinophil function, surface receptor expression, and survival. J. Clin. Invest. 78:1220-1228.

39. Howell, C. J., J. L. Pujol, A. E. G. Crea, R. Davidson, A. J. H. Gearing, P. H. Godard, and T. H. Lee. 1989. Identification of an alveolar macrophagederived activity in bronchial asthma that enhances leukotriene $\mathrm{C}_{4}$ generation by human eosinophils stimulated by ionophore A23187 as a granulocyte-macrophage colony-stimulating factor. Am. Rev. Respir. Dis. 140:1340-1347.

40. Bruijnzeel, P. L. B., P. H. M. Kuijper, S. Rihs, S. Betz, R. A. J. Warringa, and L. Koenderman. 1993. Eosinophil migration in atopic dermatitis I: increased migratory responses to $N$-formyl-methionyl-leucyl-phenylalanine, neutrophil-activating factor, platelet-activating factor, and platelet factor 4 . J. Invest. Dermatol. 100:137-142. 